\title{
HOMENAGEM A AGNELA GIUSTA
}

O texto que se segue foi escrito por Agnela da Silva Giusta e foi publicado originalmente em 1985, no primeiro número de Educação em Revista. Com essa republicação Educação em Revista homenageia com justiça a memória de nossa querida colega Agnela, falecida em 24 de fevereiro de 2013, em plena atividade como intelectual e educadora competente, sábia, arguta e inovadora, estudiosa de referenciais de vanguarda em educação e autora de contribuições que se tornaram referência no estudo das relações entre psicologia e educação no Brasil.

Graduada em Pedagogia pela Universidade Federal da Bahia em 1968, Agnela Giusta tornou-se professora nessa mesma Universidade início da década de 1970. Licenciou-se para cursar o Mestrado em Educação na Fundação Getúlio Vargas, no Rio de Janeiro, onde realizou estudo pioneiro sobre fatores determinantes da qualidade do ensino. Aluna de Circe Vital Brasil, Franco Seminério e outros pesquisadores respeitados, fez parte de um grupo importante de estudiosos da epistemologia genética e da psicologia soviética e dos desdobramentos dessas correntes de pensamento no Brasil. Ao se tornar professora na Faculdade de Educação da UFMG, em 1977, lecionou nas licenciaturas, deixando marcas perenes em seus alunos, hoje professores e pesquisadores de inúmeras áreas e instituições brasileiras. Nos embates epistemológicos e políticos dos anos de 1980, produziu textos e artigos que se tornaram diferenciais nas concepções de ensino e aprendizagem e na formação de educadores. Fez ainda parte de equipe de apoio pedagógico ao curso de Psicologia, colaborando em pesquisas sobre a formação do psicólogo na Universidade Federal de Minas Gerais e propondo transformações e o enriquecimento dessa formação. Defendia a introdução de perspectivas críticas e politicamente engajadas na escuta de grupos sociais oprimidos e na adoção de práticas educativas democráticas e inovadoras.

Cursou o doutorado em Psicologia da Educação na Universidade de São Paulo, sob a direção competente de Lino de Macedo, um dos principais 
estudiosos da teoria piagetiana no Brasil, de quem foi uma das primeiras orientandas. A tese de doutorado de Agnela se tornou referência na análise dos processos cognitivos relacionados ao fracasso escolar de alunos do ensino fundamental. A tese mostra de maneira magistral como o domínio da leitura e da escrita está intrínsecamente relacionado ao desenvolvimento da consciência crítica e à construção da subjetividade.

De volta à UFMG, colaborou na pós-graduação em Psicologia e, como pesquisadora, contribuiu para a formação de muitos estudantes interessados nas relações entre cognição e cultura, ensino, aprendizagem e fracasso escolar. Sempre ativa e atualizada, após a aposentadoria na UFMG, transferiu-se para a PUC-Minas, onde atuou em cursos de especialização, liderando a implantação de Mestrados profissionais em ensino, experiência pioneira no Brasil, com grande potencial de inovação pedagógica no ensino das diversas ciências.

Em todas essas vertentes, provocava e inseria colegas e alunos em grupos de estudos e projetos arrojados, comprometidos com o ensino e a aprendizagem de qualidade. Esse legado se expressou em diversos cursos, programas e projetos direcionados a instituições particulares e a redes públicas de ensino.

O texto aqui reproduzido é um belo exemplo da visão ampla e bem informada com que a autora abordava as relações entre psicologia e educação, a partir de uma perspectiva crítica e com base em um conhecimento consistente das bases filosóficas e epistemológicas das principais teorias em psicologia utilizadas em práticas educativas contemporâneas. Citando Henri Lefebvre, Agnes Heller e Adam Shaff, e revelando conhecimento aprofundado dos fundamentos filosóficos da análise dialética, Agnela Giusta propõe uma avaliação das perspectivas empirista, racionalista e interacionista em Psicologia a partir de uma visão original e transformadora. Critica a ênfase excessiva colocada pela teoria behaviorista sobre a modelagem do sujeito pelo ambiente, assim como critica a psicologia da Gestalt por ignorar a historicidade do sujeito psicológico. Observa que a teoria piagetiana, embora oferecendo uma perspectiva dialética na abordagem da construção do conhecimento, deixa de considerar o impacto da inserção social do sujeito nesse processo de construção. Comenta como as contribuições dos psicólogos Henri Wallon e Lev Vygotsky poderiam ajudar a superar essas limitações da abordagem interacionista, por levar em consideração de 
forma apropriada as dimensões emocional e sóciocultural dos processos de construção e de transmissão do conhecimento, de grande relevância para as concepções e práticas educacionais.

Escrito em linguagem clara e elegante, o texto tem sido lido e relido por seus alunos e colegas ao longo desses mais de 25 anos, e permanece atual e instigante. A contemporaneidade da análise proposta se evidencia na concepção de subjetividade como síntese dialética entre a objetividade do mundo e sua reconstrução internalizada pelo indivíduo, e na reafirmação do caráter social, histórico e coletivo dos processos de construção do conhecimento, Evidencia-se também na proposta de síntese entre as abordagens interacionista e sócio-interacionista dos processos educativos, de grande valor heurístico na atualidade.

Esperamos que, com essa reedição, o trabalho de Agnela Giusta continue a inspirar contribuições de qualidade na interface entre a psicologia e a educação, e na compreensão das dimensões cognitiva e sócio-afetiva dos processos educativos. 